\title{
Chetu mal: problemática urbana en una ciudad media en la costa sur del Caribe mexicano
}

Chetu mal: urban problems in an average city on the southern coast of the Mexican Caribbean

Rafael Ignacio Romero Mayo ${ }^{1}$

\section{Resumen}

A partir de su creación como Territorio Federal en 1902, la antigua ciudad de Payo Obispo, hoy ciudad de Chetumal, ha sido una permanente observadora de la historia geopolítica de la entidad federativa de la que es sede de sus poderes políticos, sin quedarse al margen de una serie de problemas urbanos que muestran la ineficiencia en materia de planeación o de aplicación efectiva de los instrumentos de su desarrollo urbano. El presente trabajo tiene como objetivo central explicar el proceso de creación y evolución del espacio urbano de Chetumal, desde la fundación de Payo Obispo en 1898, hasta la actualidad, identificando los diferentes problemas urbanos que ponen en entredicho el estatus de ciudad de Chetumal.

Palabras clave: Cadena causal, frontera, Península de Yucatán, planeación urbana, urbanismo.

Doctor en Geografía, Universidad Nacional Autónoma de México. Filiación Institucional: Profesor-Investigador de la División de Ciencias Políticas y Humanidades, Universidad de Quintana Roo, México. País: México. Correo electrónico: rafromer@ $\underline{\text { ugroo.mx }}$ 


\section{Abstract}

From its creation as a Federal territory in 1902, the old city of Payo Obispo, today the city of Chetumal, has been a permanent observer of the geopolitical history of the state which is the headquarters of its political powers without remaining outside of a series of urban problems that show the inefficiency in matters of planning or of effective application of the instruments of its urban development. The present work has as its central objective to explain the process of creation and evolution of the urban space of Chetumal, from the foundation of Payo Obispo in 1898, to the present time, identifying the different urban problems that questioned the status of the city of Chetumal.

Keywords: Border, causal chain, urbanism, urban planning, Yucatan Peninsula. 


\section{Introducción}

Presentamos un análisis del proceso de conformación histórica de Chetumal, así como una síntesis de los principales conflictos que la cuestionan como ciudad, a partir de la articulación de la planeación urbana con sus aspectos teórico-metodológicos. Este análisis se deriva de los primeros resultados de un proyecto de investigación denominado "Chetumal, ciudad fronteriza del siglo XXI. Análisis del proceso histórico de su organización espacial, 1898-2011", financiado con fondos del Programa para el Fortalecimiento de la Investigación (PROFI-UQROO-2012). Asimismo, se examina cómo, a pesar de la existencia de diversos instrumentos teóricos, metodológicos y de toma de decisiones (leyes, reglamentos y planes), Chetumal es aún una ciudad que presenta rasgos que permiten cuestionar el éxito de las políticas en materia de desarrollo urbano lo que, para una ciudad joven y media, es el principal problema que debe ser enfrentado por parte de sus gobernantes y de sus pobladores.

\section{Aspectos teóricos para el análisis y la planeación urbana}

En todo análisis de conformación urbana, la dimensión e importancia del espacio es fundamental para que dicho proceso se perciba como una manifestación concreta de la relación entre el ser humano y su entorno. Boudeville (1961) refiere, al hablar del espacio, que el individuo no solo vive en un espacio determinado, sino que además le da forma. Asevera que en dicho espacio, el hombre emplaza sus ciudades, sus caminos, e implanta cultura y civilizaciones. En este sentido, el hombre es más historiador que geógrafo, o más bien, crea la geografía casi al mismo tiempo que la historia (Boudeville, 1961, p. 5). Es importante señalar que la concepción del espacio, aunque así pudiese percibirse, no es privativa de la ciencia geográfica, ya que esta es igualmente incorporada a sus estudios por físicos, antropólogos, urbanistas ecólogos, entre otros. No obstante, tal y como lo refiere Massiris:

...el punto de partida de la conceptualización del espacio lo constituye el concepto proveniente de los físicos, para quienes el espacio, al igual que el tiempo, es una forma de existencia de la materia, mutuamente inseparables. El espacio expresa el orden de distribución de los objetos que coexisten simultáneamente (sincronía). El tiempo expresa la consecutividad de los fenómenos que se sustituyen unos a otros (diacronía). La esencia de ambos es el movimiento, de modo que entre tiempo y espacio existe una circularidad causal mediada por el movimiento de los objetos, a partir de la cual se puede hablar de la temporalidad del espacio y de la especialidad del tiempo. El tiempo es, entonces, espacio en movimiento y el espacio es tiempo relativamente estable. (2005). 
Desde la geografía crítica, el espacio, visto desde una óptica dialéctica y materialista histórica, no es percibido como una unidad absoluta, por el contrario, el espacio conlleva un componente social pleno que da paso al espacio social o a una concepción marxista del espacio. Así, Lefebvre (1974, citado por Ortega, 2000 , p. 360), establece que el espacio no responde a las condiciones naturales, ni a la historia o cultura presente en un lugar, sino que es el resultado de un proceso ligado al desarrollo de las fuerzas productivas y de las relaciones sociales de producción.

Por otra parte, la obra de Milton Santos incorpora planteamientos de Lefebvre en el sentido de que no es posible concebir o analizar ninguna formación socioeconómica sin recurrir al espacio, ya que tanto el modo de producción, como la formación socioeconómica y el espacio son categorías interdependientes. El espacio es la síntesis, siempre provisional, entre el contenido social y las formas espaciales; las ciudades no son la excepción de dicha síntesis. Cuando la sociedad actúa sobre el espacio, no lo hace como realidad física, sino como realidad social, es decir, como objetos sociales ya valorizados a los cuales la sociedad busca ofrecer o imponer un nuevo valor (Santos, 2000, p. 91).

A partir de lo anterior, el espacio debe considerarse como el conjunto indisociable del que participan, por un lado, cierta disposición de objetos geográficos, objetos naturales y objetos sociales, y por otro lado, la vida que los llena y anima, la sociedad en movimiento (Santos, 1996, p. 28).

Por su parte, Harvey sistematiza los planteamientos de Lefebvre integrando la producción del espacio con el proceso de producción social. La teoría de la producción del espacio de Harvey, trata de hacer comprensible la forma de manifestación espacial y temporal de los procesos sociales, considerando para ello la naturaleza de las expresiones, o acciones sociales que ocurren. Según Harvey:

Las prácticas espaciales y temporales, en cualquier sociedad, abundan en sutilezas y complejidades. En la medida en que están tan íntimamente implicadas en procesos de reproducción y transformación de las relaciones sociales, tiene que encontrarse la manera de describirlas y de establecer generalizaciones sobre su uso. La historia del cambio social está capturada en parte por la historia de las concepciones de espacio y tiempo, y los usos ideológicos para los cuales pueden ser colocadas aquellas concepciones. Más aún, cualquier proyecto para transformar la sociedad debe captar la punzante complejidad de las transformaciones de concepciones y prácticas espaciales y temporales (Harvey, 1990, citado por Olivera, 2005, p. 64).

En el caso concreto del espacio urbano, este debe ser entendido como algo creado, conformado y moldeado fun- 
damentalmente por procesos históricos, mediante procesos sociopolíticos (Iracheta, 1988, p. 119). En ese sentido, y en primera instancia, el espacio que parece algo homogéneo, que parece un objeto puro, es un producto de las relaciones sociales; es más, el espacio es producido como cualquier otra mercancía (Lefebvre 1977, p. 341, citado por Iracheta, 1988, p. 119-120).

Sin embargo, el proceso de desarrollo urbano, sobre todo en los países subdesarrollados, ha presentado una serie de problemas recurrentes y casi homogéneos, respecto a los países centrales. El desarrollo de centros urbanos en países considerados no desarrollados, ha traído una serie de desequilibrios, principalmente entre la oferta y demanda de habitaciones y servicios urbanos, que componen una problemática urbana específica (Singer, 1975, p. 137-138). Esta situación generó el planteamiento de la existencia de una especie de proceso antiurbano e, incluso, del reforzamiento de lo que Tomas (1996, p.111) establece como la anticiudad para referirse a la severa degradación urbana que actualmente presenta la mayor parte de las ciudades de América Latina, lo cual se atribuye a la falta de planeamiento, y a la presencia de esta (planeación) pero con una evaluación negativa en un grado tal, que se le responsabiliza directamente de la mayor parte de los problemas existentes.

Por otro lado, Santos (1996, p. 41) establece que hoy en día el fenómeno de la urbanización es avasallador en los países del tercer mundo, pero, al mismo tiempo, señala que estos países del "sur" presentan serios retrasos en su urbanización. No obstante, agrega: "El espacio sería un conjunto de objetos y relaciones que se ejercen sobre estos objetos; no entre estos específicamente, sino para los cuales ellos sirven de intermediarios. Los objetos ayudan a concretar una serie de relaciones. El espacio es resultado de la acción de los hombres sobre el propio espacio, por medio de los objetos, naturales y artificiales" (Santos, 1996, p. 68).

Estas acciones humanas sobre el espacio, mediante las cuales surgen las ciudades, contienen una serie de elementos en las que intervienen múltiples actores que visualizan o perciben el espacio desde dos perspectivas: una real y una mental (concreta y subjetiva). En ese sentido, Lefebvre (1991, p. 38) plantea tres escenarios a partir de los cuales se pueden entender los procesos de relación e intercambio (en estricto sentido de relaciones de producción) entre ciudad y territorio, ciudad y pueblo, estado y ciudad, y así sucesivamente. Dichos escenarios se sintetizan en: la práctica espacial, las representaciones del espacio y espacios de representación.

Hay que tener en cuenta que, en la actualidad, los debates respecto al desarrollo territorial o a la trasformación o aprovechamiento del espacio, pasan por tres orientaciones diferentes, dependiendo del énfasis, la mirada y el discurso en donde se ubique la problemática espacial: la económica, la urbana y la cultural (Ramírez, 2003, p. 7). En el caso concreto de lo urbano, esta orientación del debate 
territorial estudia los procesos eminentemente citadinos que dan respuesta a los problemas del crecimiento de las ciudades (la centralidad, la descentralización y la concentración), así como los problemas sociales y demográficos con ellos vinculados: la planeación y gestión territoriales, la estructura de las ciudades y los procesos que le son propios, entre otros (Ramírez, 2003, p. 7).

Desde la sociología urbana, Castells (2004, p. 15) distingue dos conjuntos bien distintos de acepciones del término urbanización: la concentración espacial de la población a partir de unos determinados límites de dimensión y densidad; la difusión del sistema de valores, actitudes y comportamientos que resume bajo la denominación de "cultura urbana". Así, el término urbano designará una forma de ocupación del espacio por una población (Castells, 2004, p. 16).

En este punto, la planeación urbana cobra un papel relevante como instrumento de política pública para impulsar el ordenamiento del espacio y del territorio. En ese sentido, los instrumentos de planeación no son solamente enunciaciones técnicas y metodológicas que plasman elementos normativos de planeación y perspectivas urbanísticas de acuerdo con circunstancias específicas socioespaciales, sino que dichos instrumentos documentales de toma decisión pueden llegar a ser letra muerta, ya que suele suceder que la planeación se subordina a intereses políticos y económicos, por encima de los intereses y necesidades sociales.
El estudio sobre la problemática urbana, razón de esta investigación, coincide plenamente con la necesidad imperante de referirnos a la planificación urbana, como ya se señaló con anterioridad, la cual, a su vez, es el objeto real de la sociología urbana, lo que nos sitúa frente a dos problemáticas diferentes:

Los remedios dirigidos a hacer frente a las "insuficiencias" del proceso de industrialización en el aspecto de consumo y, en particular, de consumo de bienes colectivos. Y la gestión técnicoeconómica de unidades espaciales cada vez más extensas y complejas (Castells, 2006, p. 195, 197).

Dentro de los elementos que debe atender la planeación urbana, sobre todo en las grandes ciudades, aunque ello no deja de ser aplicable a las ciudades medias y pequeñas, está el responder a cinco tipos de retos: nueva base económica, infraestructura urbana, calidad de vida, integración social y gobernabilidad. Solamente generando una capacidad de respuesta a estos retos, podrán, por una parte, ser competitivas hacia el exterior e insertarse en los espacios económicos globales y, por otra, garantizar a su población los mínimos necesarios de bienestar para que la convivencia democrática pueda consolidarse (Borja \& Castells, 2002, p. 144-145). La respuesta a los retos planteados con anterioridad, requiere de un proyecto de ciudad, de un proyecto urbano, en concreto: de hacer ciudad -y aquí es donde interviene la planeación urbana-. 
Sin embargo, la eficacia de estos planes o proyectos de ciudad, visualizados hacia el futuro, dependerá de muchos factores, entre los que se quiere destacar uno en particular para efectos de esta investigación:

Un plan estratégico debe construir o modificar la imagen que la ciudad tiene de sí misma y que tiene en el exterior. En la medida en que es una respuesta a una sensación de crisis, que resulta de la voluntad de insertarse en nuevos espacios económicos y culturales globales y que pretende integrar a una población que se siente muchas veces excluida o poco tenida en cuenta, el proyecto-ciudad es un proyecto de comunicación y de movilización ciudadana y de promoción interna y externa de la urbe (Borja \& Castells, 2002, p 150).

Ahora bien, precisando el concepto de planeación, esta se refiere a:

[...] la actividad interdisciplinaria encaminada a la preordenación de una determinada operación; serie de operaciones o acción compleja de carácter general y amplio en tanto sus fines u objetivos, se concretiza en planes generales, lineamientos y políticas debiendo ser atendido como un proceso de carácter integral en los aspectos sociales, económicos, políticos y territoriales (Landa, citado por Ordaz y Saldaña, 2005, p. 35).

Para Ander Egg (2002), la planeación es esencialmente el proceso de adopción de técnicas prescriptivas apoyadas en proyecciones estadísticas, evaluaciones cuantitativas y estimaciones cualitativas, para prever el futuro en función de objetivos, metas, políticas y programas establecidos.

Iracheta $(2002$, p. 68) se refiere a la planeación como "una herramienta para lograr el desarrollo en función de objetivos claramente definidos, y como un instrumento para equilibrar lo que se pretende con lo que es posible realizar". El carácter político de la planeación deriva del propio proceso de acuerdos sobre modos y formas de desarrollo y sobre las decisiones que cotidianamente se toman para avanzar en el rumbo acordado. La planeación deriva de la política y es parte de la política.

Asimismo, Miklos (2001, p. 3) establece que la planeación representa la búsqueda creativa, organizada, sistemática, sistémica, y comprometida de incidir sobre el futuro. Planear implica formular escenarios y determinar objetivos y metas, estrategias y prioridades, asignar recursos, responsabilidades y tiempos de ejecución, coordinar esfuerzos, evaluar etapas, resultados, y asegurar el control de los procesos.

Toda planeación es fundamentalmente una elección sobre el futuro. Presupone la capacidad de escoger, entre varias alternativas, la que resulte más conveniente. Los planeas y la planeación se refieren necesariamente a actividades futuras, cuya orientación y propósito han sido trazados de antemano (Miklos, 2001, p. 8). 
Miklos y Tello (2005, p. 59) coinciden con las anteriores propuestas y establecen que la planeación se orienta a obtener o a impedir un determinado estado futuro de cosas. Así se dirige al futuro aportando decisiones presentes.

En ese sentido, y para los intereses de la administración pública municipal, la planeación se entiende como:

[...] un medio que permite el desempeño eficaz de la responsabilidad del estado y de sus municipios, sobre su desarrollo integral, y deberá atender a la consecución de los fines y objetivos políticos, sociales, económicos y culturales, contenidos en la Constitución Política de los Estados Unidos Mexicanos y en la Constitución Política de los Estados de la Federación.

$\mathrm{Al}$ respecto, el artículo 115 de la Constitución mexicana establece en su fracción tercera:

Los municipios tendrán a su cargo las funciones y servicios públicos siguientes:

a) Agua potable, drenaje, alcantari llado, tratamiento y disposición de sus aguas residuales;

b) Alumbrado público;

c) Limpia, recolección, traslado, tratamiento y disposición final

de residuos;

d) Mercados y centrales de abasto:

e) Panteones;

f) Rastro;

g) Calles, parques y jardines y su equipamiento; h) Seguridad pública, en los térmi nos del artículo 21 de esta Cons titución, policía preventiva mu nicipal y tránsito;

i) Los demás que las Legislaturas locales determinen según las condiciones territoriales y so cioeconómicas de los Municipios, así como su capacidad administrativa y fi nanciera. (Constitución Política de los Estados Unidos Mexica nos, 2012, p. 78-79)

Derivado de lo anterior, podemos suponer que, en términos del desarrollo urbano de ciudades medias como Chetumal, no debería haber problemas para asegurar una adecuada planeación urbana, ya que es un aspecto claramente establecido por el máximo instrumento legal del país. No obstante, como se verá más adelante, los problemas que existen en Chetumal contravienen los derechos de los ciudadanos a tener una ciudad ordenada y con servicios públicos de calidad, y ponen en evidencia a las autoridades municipales en cuanto al incumplimiento o a su incapacidad para garantizar el disfrute de ese derecho constitucional por parte de sus gobernados.

\section{Origen histórico de Payo Obispo (hoy Chetumal)}

Como secuencia de la explotación económica y racial de la que eran objeto los mayas, a mediados del siglo XIX estalló el conflicto regional denominado Guerra de Castas, el cual duró más de 50 años y 
permeó de manera directa en las condiciones prevalecientes en la península de Yucatán, sobre todo en la parte oriental, en donde actualmente se localiza el estado de Quintana Roo.

Con la Guerra de Castas se dio una nueva fisonomía territorial y el surgimiento o repoblamiento de lugares anteriormente habitados y abandonados de manera posterior a la colonización española (entre ellos Cozumel e Isla Mujeres). Al respecto, Dachary y Arnaiz (1993, p. 75), señalan: "La nueva distribución de la población y organización espacialadministrativa derivada de la Guerra de Castas tiene, además de la zona liberada de los mayas, la denominada República de los Macehuales y la colonia de Belice, las nuevas poblaciones mexicanas de las islas del mar Caribe".

En 1850 y casi de manera inmediata al inicio de la guerra, surgió el culto a la Cruz Parlante, y con ello la fundación de Chan Santa Cruz (hoy Felipe Carrillo Puerto) y, en torno a esto, una estructura social basada en una relación religiosamilitar que contribuyó de manera importante al fortalecimiento ideológico y espiritual de los mayas; con ello se prolongó el conflicto por más de medio siglo. Es importante establecer que al concentrarse los indios en los bosques de Chan Santa Cruz y teniendo el paso libre hacia Bacalar, se inició una estrecha relación de estos con los colonos ingleses establecidos al otro lado del río Hondo y comenzó un comercio ilegal basado fundamentalmente en el intercambio de pertrechos de guerra (municiones, pólvora, armas, etc.) para los mayas, a cambio de la explotación de los recursos forestales por parte de los ingleses, en territorio controlado por los mayas. Al respecto, Toussaint (2004, p. 123-124) menciona:

Desde antes de consumarse la independencia nacional, una insignificante colonia inglesa tomó posesión de una pequeña parte del territorio yucateco en la costa sureste de la península; pero la funesta guerra a que se ha hecho referencia (Guerra de Castas, las cursivas son mías), imposibilitando la vigilancia de nuestras fronteras naturales e históricas, ha acrecentado ilegalmente el territorio de esa colonia. El espíritu mercantil, absorbente por naturaleza, no ha sido allí contenido en los justos límites en que las sociedades cultas lo mantienen, y tal parece que la metrópoli inglesa no ha fijado su atención en la naturaleza de ese comercio que mantiene el salvajismo de una masa de infortunados mexicanos, poniendo en sus manos las armas fratricidas para recibir en cambio inmensos bosques de maderas preciosas, que impunemente se arrebatan a la riqueza nacional, haciendo jirones el territorio de la patria.

El texto anterior sustentó parte de la solicitud hecha por la Legislatura del Estado de Yucatán al presidente Porfirio Díaz el 28 de septiembre de 1892, para que se diera una intervención del poder 
federal a fin de erradicar por completo el conflicto iniciado en 1847, estableciendo, de común acuerdo con la corona británica, los límites fronterizos y proponiendo que fuera el río Hondo la línea divisoria natural.

También, la Junta Auxiliar de Mérida de la Sociedad Nacional de Geografía y Estadística solicitó al presidente Díaz, en septiembre de 1892, la definición de los límites alegando, al igual que en el caso anterior, que solo la definición de límites podría coadyuvar al sometimiento de los "indios rebeldes". En la conclusión de la solicitud se lee:

[...] ocurrimos suplicando, se sirva definir los tratados diplomáticos que tiendan al arreglo final de las cuestiones pendientes con la Gran Bretaña, respecto a los derechos que puedan quedarse sobre el territorio de Belice y sus límites ciertos, dejándolo todo, por nuestra parte, encomendando a su justificación, unida al conocimiento cierto que tiene de todos los antecedentes sobre este particular, y del conocimiento también del territorio que indiscutiblemente corresponde a la nación, y que en todo caso nunca será menos del que se extienda hasta el conocido río Hondo, hacia el sur de este estado (Toussaint, 2004, p. 130).

Estas propuestas y solicitudes, entre otras más, dieron fruto el 8 de julio de 1893 , cuando los gobiernos de México y de la Gran Bretaña, por intermedio de sus representantes plenipotenciarios firmaron el Tratado de Límites Mariscal-St. John entre los Estados Unidos Mexicanos y Honduras Británica. Dicho tratado fue ratificado cuatro años después, añadiendo algunos aspectos importantes como el aseguramiento, a perpetuidad, para que los buques de la marina mercante de México pudiesen navegar libremente en las aguas territoriales de la colonia británica en una zona ubicada al sur del cayo Ambergrís.

Hacia finales del siglo XIX, el gobierno federal promovió la idea de crear un centro de población a las orillas de la bahía de Chetumal, en la frontera con la colonia británica. Es así como surge la Población de Payo Obispo (hoy Chetumal), fundada oficialmente por Othón P. Blanco, el 5 de mayo de 1898 (Figura 1).

No obstante, en la época, las condiciones prevalecientes eran de total carencia, por lo que la vida de los primeros pobladores de Payo Obispo transcurrió en la mayor penuria y con una evidente ausencia de servicios públicos (agua potable, alumbrado público y energía eléctrica en los hogares, colecta y manejo de basura, traza urbana, calles y avenidas pavimentadas, guarniciones y banquetas, vigilancia -a excepción de la que realizaba la Armada de México-, vías de acceso terrestre desde otras regiones del país, y abasto, entre otros). Las mercancías de consumo diario, ropa, calzado, implementos agrícolas rudimentarios y muy escasos medicamentos, venían de la población beliceña de Corozal. La comunicación cablegráfica con el interior 
Figura 1.- Ubicación de Payo Obispo (Chetumal) a finales del siglo XIX.

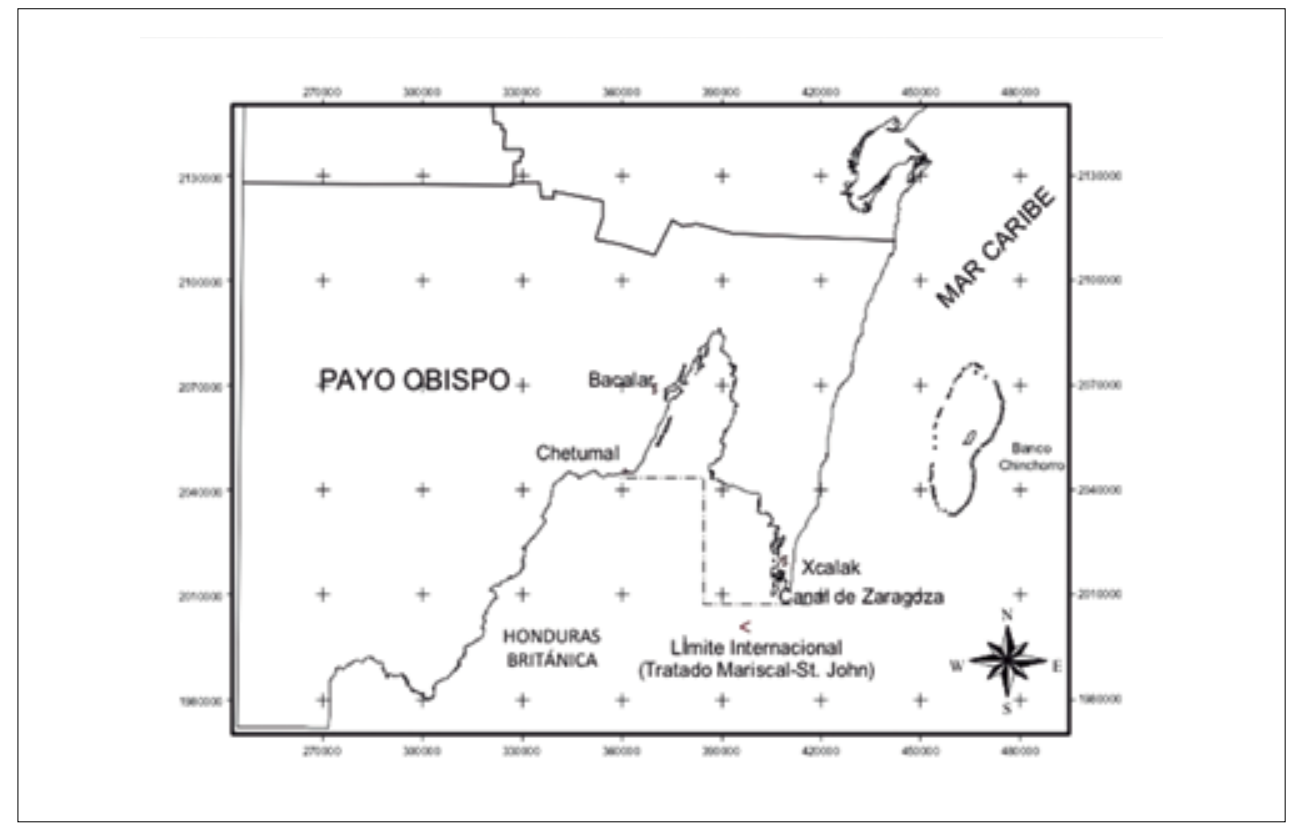

Fuente: Elaboración propia.

del país solamente era posible enviando pequeñas embarcaciones hasta algún puerto importante de las Repúblicas de Guatemala y Honduras (Hoy, 1998, p. 43).

\subsection{De Payo Obispo a Chetumal. Primeros conflictos urbanos}

Después de sus primeros treinta años de vida como ciudad fronteriza y de haber soportado procesos de fragmentación y reconstitución geopolítica, a partir de sendos decretos presidenciales en los años de 1902, 1913, 1915, 1931 y 1935, y una vez decretado en definitiva el Territorio de Quintana Roo, en 1936 el gobernador Rafael E. Melgar resolvió modificar las denominaciones geográficas de origen religioso, y con ellas, la ciudad de Payo Obispo cambió su nombre por el de Chetumal (forma modificada del maya Chactemal) en recuerdo al pontón capitaneado por Othón P. Blanco, que permitió la fundación de la ciudad, aunque la delegación municipal mantuvo el nombre original (Payo Obispo). A partir de entonces, Quintana Roo inició un importante despegue económico, político y social con una estructura territorial basada en cuatro delegaciones (Cozumel, Isla Mujeres, Payo Obispo y Felipe Carrillo Puerto), las cuales eran administradas por un delegado político, quien era nombrado directamente por el gobernador del territorio. 
La explotación de maderas preciosas, de maderas duras tropicales y del chicle, representaba el sustento de la época para el Territorio. Sin embargo, esta explotación comenzó a darse de manera irracional afectando gravemente dichos recursos, sobre los que había mucho interés por parte de empresas externas. El último auge del chicle y la madera en la zona se dio en el periodo comprendido entre 1930 y 1950, acompañado de un proceso de poblamiento y movimiento poblacional muy particular.

Como parte de su imagen inicial, la ciudad de Chetumal fue trazada a partir de un concepto rectilíneo y cuadriculado, es decir con calles y avenidas rectas pero amplias que permiten un flujo eficiente y constante. Las primeras casas construidas fueron de madera a partir de un concepto de tipo victoria$n o^{2}$ (por influencia británica a través de lo que hoy es Belice) y que se pueden encontrar en casi todo el Caribe insular y continental.

Chetumal careció de muchos servicios desde su creación, o los pocos que tenía eran deficientes: sistema de drenaje, suministro de agua potable, energía eléctrica, calles y avenidas pavimentadas, banquetas, guarniciones, vías de comunicación aérea y terrestre, entre otras.

2 Este tipo de viviendas se caracteriza por paredes construidas con placas de madera machimbradas (sistema de maderas ensambladas con bordes rebajados) y cubiertas de lamina metálica. Como sistema de captación de agua se utilizaban curbatos (cisternas de madera sobre el nivel del terreno).

\subsection{La huella del huracán Janet en la fisonomía urbana de Chetumal}

En septiembre de 1955, Chetumal fue presa de uno de los desastres naturales más devastadores de su corta historia, al menos del que se tenga registro: el huracán Janet. La ciudad de Chetumal y la costa sur del territorio fueron azotados por dicho meteoro, así, la mañana del 28 de septiembre, cuando los pocos sobrevivientes fueron saliendo de sus refugios o de lo que quedó de sus endebles casas de madera, se dieron cuenta que lo que habían construido en medio siglo había prácticamente desaparecido. Hoy (1998) narra:

El colmo de la desgracia para la población de Chetumal y la región sur del Territorio fue el embate del horripilante ciclón Janet la noche del 27 de septiembre de 1955. Todas las propiedades prediales, muchas vidas, incluso muebles y modestísimas pertenencias de la población se perdieron. Hubo cuadras de dolor inmenso y de tragedia indescriptible. Huérfanos, viudas, madres que perdieron a sus hijos y todos sin alimento ni agua potable ni techo. Así, desolador, fue el amanecer de Chetumal aquel 28 de septiembre.

$\mathrm{Y}$ es que no solo fueron las pérdidas humanas -en este caso lo más importantesino también las pérdidas materiales, la destrucción de una ciudad, la emigración que ello provocó y la pérdida de la mayor parte forestal de la región sur que quedó en el suelo y que prácticamente definió 
el rumbo del otrora enclave forestal. El Janet marcó el destino de la actividad económica más importante, la forestal, ya que decayó la actividad chiclera en la región, por lo que se impuso la necesidad de rescatar las maderas finas derribadas y dañadas que quedaron en pie. Los costos de explotación subieron de manera considerable por lo inaccesible que se tornó la zona. En términos generales, hubo que partir de cero y reconstruir la ciudad de Chetumal y la economía regional.

La ciudad de Chetumal fue reinventada y refundada a partir del Janet. Los antiguos habitantes, testigos de dicho fenómeno, relatan, aún hoy día, cómo la ciudad buscó ampliar sus asentamientos urbanos hacia zonas más alejadas del mar y en áreas relativamente más elevadas.

Hacia el ocaso de los años 60, después del huracán Janet, con una capital prácticamente destruida y reinventada, con graves condiciones económicas y con una economía en crisis debido al declive de la producción forestal, el Territorio de Quintana Roo se encontraba ante un panorama incierto. Aunado a lo anterior, la infraestructura estatal era casi nula y el número de población total no era mayor a los 80.000 habitantes $^{3}$.

Sin embargo, el proceso de colonización dirigida, impulsada por el gobierno federal, el desarrollo de un proyecto en la costa y en su frontera marítima con Belice

De acuerdo con los datos dados a conocer por el Instituto Nacional de Estadística, Geografía e Informática (INEGI) en el documento Síntesis de Población 1930-1980, en 1970 la población total del estado era de 88.150 . para la ampliación de las cooperativas pesqueras, así como el desenvolvimiento incipiente de la actividad turística, sobre todo en la costa norte del Territorio, permitirían ayudar a la recuperación, al abrirse nuevos caminos y sentar las bases para nueva infraestructura, para poder retener a la población y justificar la creación de Quintana Roo como nueva entidad federativa, situación que se dio el 8 octubre de 1974 mediante decreto presidencial, siendo su capital la ciudad de Chetumal (Figura 2).

En este escenario, Chetumal siguió conservando su estado de ciudad capital y sede de los poderes del estado, aunque su crecimiento se mantuvo constante al atraer personas de diferentes latitudes, debido a su creciente sistema burocrático y de oferta educativa, aunado a las indudables e indiscutibles condiciones de tranquilidad y belleza de su entorno. Desde su creación como Payo Obispo en 1898, la ciudad ha tenido, prácticamente, un comportamiento sostenido en cuanto al incremento histórico de su población, tal y como se observa en la tabla 1, lo que permite afirmar que, si bien no es una población numerosa, es significativa en cuanto a su tenencia.

Lo que parecería ser un escenario idóneo para poder hablar de una ciudad joven, moderna y bien ordenada, sobre todo en aspectos urbanos y de servicios, lo cual es independiente de su belleza escénica y natural, nos lleva a afirmar que como ciudad media y joven, Chetumal tiene una serie de problemas que ponen en entredicho tanto su estatus de ciudad, como 
Figura 2.- Primera división territorial de Quintana Roo como Entidad Federativa en 1974.

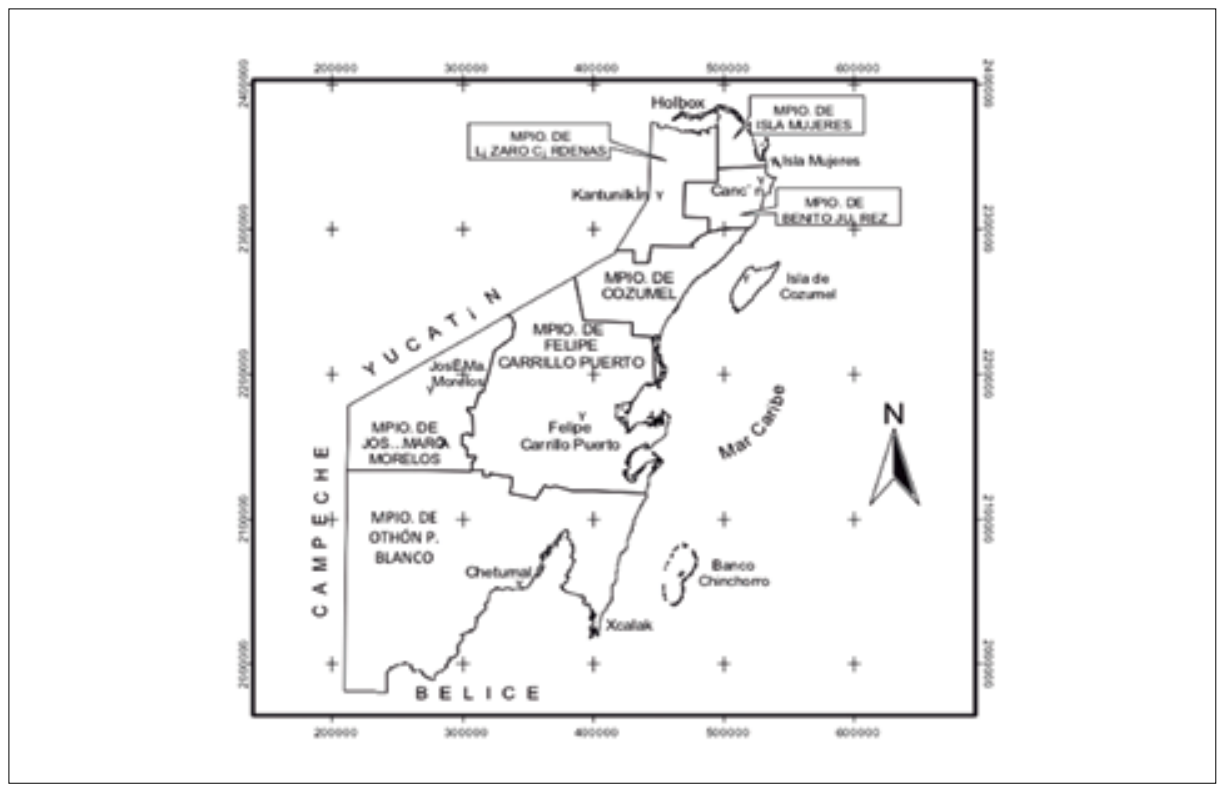

Fuente: Elaboración propia.

Tabla 1. Evolución de la población de Chetumal

\begin{tabular}{|c|c|}
\hline CENSO & HABITANTES \\
\hline 1910 & 2,112 \\
1921 & 1,773 \\
1930 & 2,790 \\
1940 & 4,672 \\
1950 & 7,247 \\
1960 & 12,855 \\
1970 & 23,685 \\
1980 & 56,709 \\
1990 & 94,158 \\
2000 & 121,602 \\
2005 & 136,825 \\
2010 & 151,243 \\
\hline
\end{tabular}

Fuente: DGE para los censos de 1910 a 1970;

INEGI para los censos de 1998 a 2010. 
el falso discurso de sus gobernantes que eternamente han expresado que todo estaba bien y que la ciudad iba por buen camino.

\section{Deterioro urbano de Chetumal}

Además de lo establecido en el artículo 115 constitucional que, entre otros aspectos, dota de autonomía a los municipios para poder planear su desarrollo y asegurar servicios que tiendan a mejorar la calidad de vida de la población, existen otros instrumentos legales, de observancia y alcance municipal, que regulan de forma particular los aspectos de planeación urbana y desarrollo municipal, en este caso del municipio de Othón P. Blanco, cuya cabecera municipal es la ciudad de Chetumal. Entre dichos instrumentos se pueden mencionar los siguientes: Plan de Desarrollo Municipal de Othón P. Blanco; Reglamento de desarrollo urbano y seguridad estructural del municipio de Othón P. Blanco; Reglamento de aseo urbano del municipio de Othón P. Blanco, Quintana Roo; Ley Orgánica Municipal; Bando de Policía y Buen Gobierno; Programa municipal de desarrollo urbano del área metropolitana del municipio de Othón P. Blanco; Ordenamiento territorial del área metropolitana; además de las leyes y reglamentos de índole estatal que son observables por todos los municipios que integran la estructura geopolítica del estado de Quintana Roo.

En el caso de los Planes de Desarrollo Municipal y de Desarrollo Urbano del Área Metropolitana, toma especial importancia, desde la perspectiva del desarrollo urbano, la concentración poblacional que existe en Chetumal.

El Plan de Desarrollo Urbano Municipal reconoce que el crecimiento urbano se está produciendo en extensión, y con baja densidad, básicamente hacia el norte de Chetumal, y en algunos casos hacia zonas no aptas por ser inundables, lo que obliga a extender redes de infraestructura, al mismo tiempo que se da un bajo aprovechamiento de las existentes. Asimismo, se reconoce que Chetumal crece, a la vez que las localidades de apoyo decrecen, con la consiguiente pérdida de espacios funcionales para organizar la estructuración urbana (PDU, 2011, p. 36).

Es importante señalar que, con base en el propio Plan de Desarrollo Urbano, se reconoce que:

[...] la ciudad de Chetumal, en el ámbito específico del polígono de su área metropolitana, presenta aptitudes diferenciadas tanto por la estructura urbana actual y por las tendencias de crecimiento, como por las características naturales del territorio. En este aspecto puede afirmarse que aunque en rigor la ciudad de Chetumal, desde el punto de vista meramente natural se encuentra sobre un área inadecuada para el establecimiento humano, por su susceptibilidad a accidentes y riesgos hidrometeorológicos tales como huracanes, y por la susceptibilidad a inundaciones de sus partes bajas, la posición geopolítica del centro de población y el nivel de desarrollo alcanzado hacen que sea apta para el desarrollo urbano. (PDU, 2011, p. 55). 
Lo anterior es, sin duda alguna, una afirmación contradictoria por parte de las autoridades, toda vez que sostienen que aunque la ciudad se encuentra sobre un área inadecuada, sí es apta para el desarrollo urbano. No podemos pasar por alto que la tendencia de crecimiento de Chetumal en los últimos 15 años ha sido hacia su parte norte, incluyendo las tendencias, de acuerdo con el Plan de Desarrollo Urbano del Área Metropolitana (Figura 3), donde se localizan zonas altamente inundables.

Figura 3. Tendencias de crecimiento urbano de Chetumal.

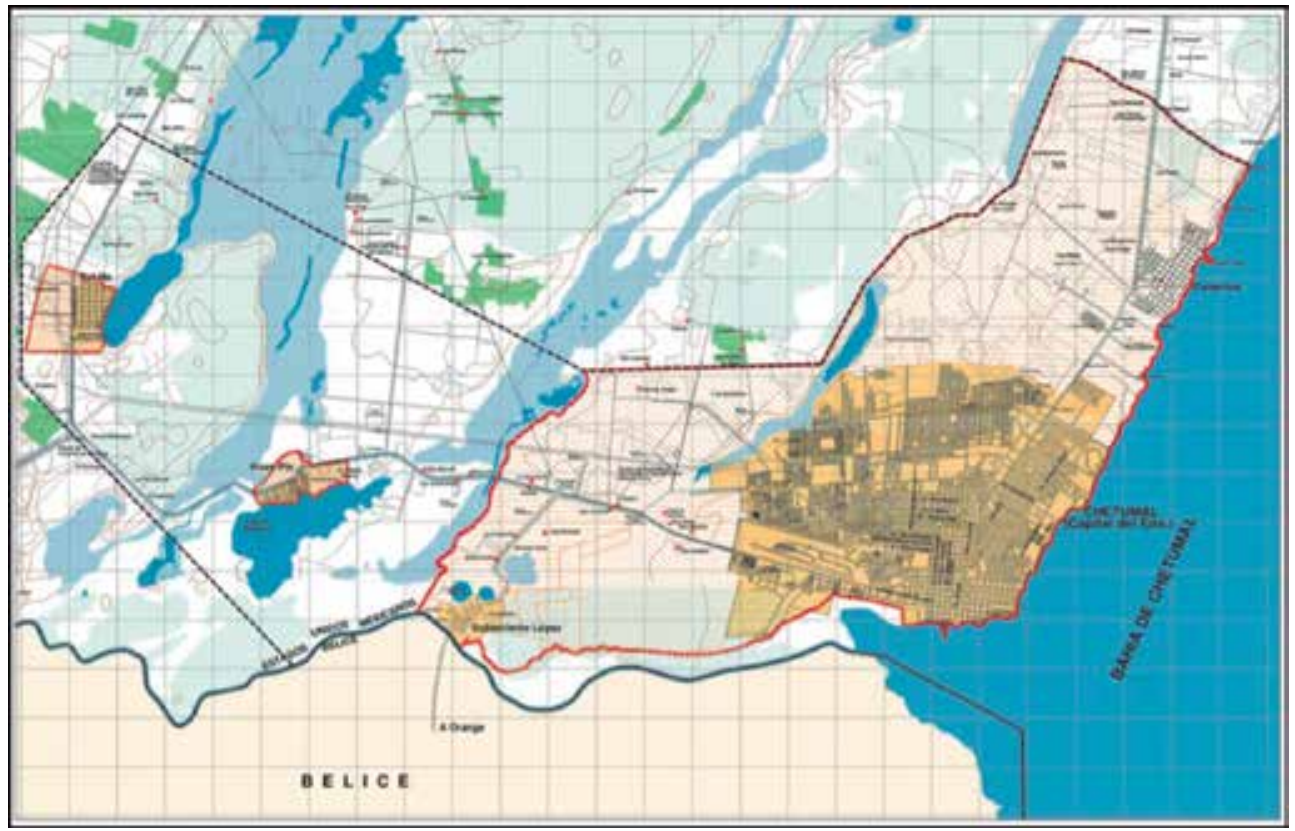

Fuente: Plan de Desarrollo Urbano y Área Metropolitana.

Adicionalmente, en su parte baja, colindante con la bahía, la ciudad ha resentido históricamente los problemas de erosión costera y de desfondes en las calles de la parte cercana a la bahía, debido a lo permeable del subsuelo y a la intrusión de agua marina a través de cavidades en el subsuelo.
Se reconoce también en el Plan de Desarrollo Urbano, la existencia de déficits en materia de agua potable (solo el $66 \%$ de las viviendas de Cheutmal cuenta con ella) y de drenaje sanitario (el $83.1 \%$ carece del servicio), lo que conlleva la contaminación del manto freático debido a una serie de descargas directas en muchas zonas habitacionales. 
Dentro de los aspectos que deben abordarse en cuanto a infraestructura, es importante mencionar los siguientes (PDU, 2011, p. 111-112):

Se necesita incrementar el número de predios conectados al sistema de tratamiento de aguas residuales en toda el área metropolitana, con el fin de reducir las descargas que lleven a la contaminación del manto freático y de los cuerpos de agua, de acuerdo con las cantidades establecidas en el apartado anterior.

Implementar un adecuado sistema de recolección de basura y de tratamiento de residuos sólidos.

Consolidar el suministro de agua mediante el aumento de las redes de distribución, de acuerdo con lo establecido en el apartado anterior, y propiciar las conexiones domiciliarias a las redes.

En el rubro de vialidades y señalización, aun cuando la ciudad presenta un trazado cuadriculado, con avenidas y calles amplias, existen serios problemas en la calidad de sus calles y avenidas, a lo que habría que sumar una deficiente señalización y la ausencia o deterioro de sus banquetas (andadores) y guarniciones. Es evidente la falta de inversión, así como lo es la ejecución de obras de pésima calidad bajo esquemas de corrupción, tanto en las licitaciones y asignaciones de la obra pública por presupuestos inflados pero con la utilización de materiales de pésima calidad.

Chetumal es una ciudad que no escapa a la problemática que, en general, tienen muchas ciudades de México y de América Latina. Problemas y carencias aunados a los aspectos económicos y de empleo que reflejan la insuficiencia de servicios con sus consecuentes situaciones de insalubridad, la falta de vivienda con sus secuelas de hacinamiento, la falta de equipamiento que no permite el desarrollo de los pobladores, y la misma necesidad de habitar espacios agradables (Sánchez, 2008, p. 250).

La siguiente es una síntesis de los problemas urbanos y de servicios que presenta actualmente la ciudad de Chetumal, aunque - vale aclararlo- estos problemas los ha venido arrastrando desde hace varias administraciones de gobierno municipal.

Calles deterioradas casi en su totalidad (baches, desgaste del pavimento, hundimientos).

Calles sin nivelación, lo que ocasiona estancamiento de aguas pluviales en zonas de circulación vehicular.

Falta de banquetas y guarniciones en muchas calles y avenidas, sobre todo en colonias periféricas al centro de la ciudad.

Falta de señalamiento en gran parte de las calles y avenidas periféricas al centro de la ciudad. Semaforización insuficiente.

Colecta de basura ineficiente e insuficiente. Se refleja en la proliferación de basura en muchas zonas de la ciudad.

Proliferación de cacharros, cascajo, muebles, tanto en los camellones centrales como en calles de las zonas populares. 
Esto es reflejo de una falta de cultura en gran parte de la población respecto al manejo responsable de sus residuos y de sus bienes.

- Sistemas de concentración de basura sin tecnología apropiada para evitar la emisión de metano y lixiviados. Falta de un relleno sanitario en forma.

- Drenaje pluvial y sanitario deficiente.

- Existencia de descargas de aguas residuales y pluviales hacia la bahía de Chetumal y otros cuerpos de agua.

- Ausencia de áreas verdes de calidad, sustituidas por camellones, parques y avenidas llenas de maleza.

- Proliferación de terrenos baldíos cubiertos de maleza.

- No existen niveles de construcción con base en un plan de desarrollo habitacional.

- Ineficiencia en la aplicación de los planes de desarrollo urbano.

- Iluminación deficiente en ciertas zonas de la ciudad.

- Sistema de transporte anárquico y en manos de sindicatos corruptos.

Con base en el análisis anterior, se puede establecer que el rostro urbano de Chetumal presenta huellas imborrables de sus distintas etapas de crecimiento, sobre todo en su imagen urbana. La planeación urbana en el país, que por definición es responsabilidad constitucional de los estados y municipios, ha sido penosamente deficiente. Esta deficiencia se traduce en el hecho real de que la planeación urbana en México no coadyuva de forma efectiva al crecimiento sostenido de la economía, no incide de forma significativa en el bienestar social de la población y no asegura la sustentabilidad de nuestras ciudades (Rébora, 2000, p. 123); y, por supuesto, Chetumal no es ajena a esta realidad.

\section{Conclusiones}

Históricamente, Chetumal fue un punto importante para erradicar el conflicto regional iniciado por los mayas en 1847. Su creación como zona urbana fue estratégica para el establecimiento de una aduana marítima-terrestre en la nueva frontera mexicana de finales del siglo XIX. Sin embargo, como ciudad, ha tenido una serie de condiciones y circunstancias que la hacen padecer una serie de problemas urbanos que, en estos tiempos y tratándose de una ciudad joven y de tamaño medio, no debería soportar. Y esto, al menos en teoría, podemos afirmarlo, si consideramos que existe una serie de instrumentos de planeación y de toma decisiones en materia de desarrollo urbano.

Los resultados —derivados del análisis realizado a su Plan de Desarrollo Urbano y de su Área Metropolitana, y a los aspectos conceptuales sobre lo que es la planeación urbana y el desarrollo del espacio urbano-, dejan claro, por un lado, el incumplimiento de los elementos metodológicos a partir de los cuales debe darse la planeación de la ciudad y, por otro, la falta de políticas públicas 
en materia de planeación, lo que refleja la existencia de condiciones que ponen en entredicho su estatus de ciudad y su acceso a mejores condiciones de calidad de vida de sus habitantes.

Chetumal está en manos de sus tomadores de decisiones, y la solución a su deterioro urbano es una condición importante para mejorar los servicios públicos que reciben sus pobladores, bajo el supuesto del derecho constitucional que obliga a los municipios a brindar dichos servicios. 


\section{Literatura citada}

Ander, E. (2002). Introducción a la planificación. Buenos Aires: Lumen.

Arnaiz, S. (1993). Génesis de la frontera. En Centro de Investigaciones de Quintana Roo. Estudio integral de la frontera México-Belice. Análisis socieconómico. Tomo I. Chetumal: Centro de Investigaciones de Quintana Roo.

Boisier, S. (1999). Teorías y metáforas sobre el desarrollo territorial. Santiago: Comisión Económica para América Latina y el Caribe.

Borja, J. \& Castells, M. (2002). Local y global. La gestión de las ciudades en la era de la información. México, D. F.: Taurus.

Boudeville, J-R. (1961). Les espaces économiques, Paris: Press Universitaires de France.

Constitución Política de los Estados Unidos Mexicanos. (2012, 25 de junio). Última Reforma. En Diario Oficial de la Federación. México, D. F.: Cámara de Diputados del H. Congreso de la Unión.

Castells, M. (2004). La cuestión urbana. México, D. F.: Siglo XXI.

Castells, M. (2006). Problemas de investigación en sociología urbana. México, D. F.: Siglo XXI.

Dirección General de Estadística -DGE-. (1921). Censo general de habitantes. México.

Dirección General de Estadística -DGE-. (1930). Quinto Censo General de Población. México.

Dirección General de Estadística -DGE-. (1940). Sexto Censo General de Población. México.

Dirección General de Estadística -DGE-. (1950). Séptimo Censo General de Población. México.

Dirección General de Estadística -DGE-. (1960). V VIII Censo General de Población. México.

Dirección General de Estadística -DGE-. (1970). X XIX Censo General de Población. México.

Hoy, C. (1998). Breve historia de Quintana Roo. Navegaciones de la memoria. Chetumal: Gobierno de Quintana Roo/Consejo Nacional para la Cultura y las Artes.

\begin{tabular}{l|l}
\hline 166 & Rafael Ignacio Romero Mayo
\end{tabular} 
Instituto Nacional de Estadística y Geografía -INEGI- (1980). X Censo General de Población y Vivienda, México.

Instituto Nacional de Estadística y Geografía -INEGI- (1990). XI Censo General de Población y Vivienda, México.

Instituto Nacional de Estadística y Geografía -INEGI- (2000). XII Censo General de Población y vivienda, México

Instituto Nacional de Estadística y Geografía -INEGI- (2010). XIII Censo General de Población y Vivienda, México.

Iracheta, A. (1988). Hacia una planeación urbana crítica. México, D. F.: Universidad Autónoma Metropolitana-A/Gernika.

Iracheta, A. (2002). Notas sobre desarrollo y planeación regional en México. En J. Delgadillo \& A. Iracheta (coords.). Actualidad de la investigación regional en el México central. México, D. F.: Unam-Crim/El Colegio Mexiquense/El Colegio de Tlaxcala/ Plaza y Valdés.

Lefebvre, H. (1991). The production of space. Oxford: Blackwell Publishing.

Massiris, A. (2005). Fundamentos conceptuales y metodológicos del ordenamiento territorial. Tunja: Universidad Pedagógica y Tecnológica de Colombia.

Miklos, T. (2001). Criterios básicos de planeación. En T. Miklos (coord.) Las decisiones políticas. México, D. F.: Siglo XXI/Instituto Federal Electoral.

Miklos, T. \& Tello, M. E. (2005). Planeación prospectiva. Una estrategia para el diseño del futuro. México, D. F.: LIMUSA-Noriega/Centro de Estudios Prospectivos/ Fundación Javier Barrios Sierra, A. C.

Olivera, P. (2005). La construcción de los espacios sociales en el contexto de la globalización. En C. Téllez \& P. E. Olivera (coords.). Debates en la geografía contemporánea. Homenaje a Milton Santos. México, D. F.: El Colegio de Michoacán/Embajada de Brasil/FFL-Unam/Universidad de Guadalajara.

Ordaz, V. Y. \& Saldaña, G. E. (2005). Análisis y crítica de la metodología para la realización de planes regionales en el estado de Guanajuato. Guanajuato: Universidad de Guanajuato, Facultad de Arquitectura.

Ortega, J. (2000). Los horizontes de la geografía. Teoría de la geografía. Madrid: Ariel Geografía. 
Ramírez, B. R. (2003). Modernidad, posmodernidad, globalización y territorio. Un recorrido por los campos de las teorías. México, D. F.: Universidad Autónoma MetropolitanaX/Miguel Ángel Porrúa.

Rébora, A. (2000) ¿Hacia un nuevo paradigma de la planeación de los asentamientos humanos? Políticas e instrumentos de suelo para un desarrollo urbano sostenible, incluyente y sustentable. El caso de la región oriente en el Valle de México. México, D. F.: Universidad Nacional Autónoma de México, Programa Universitario de Estudios sobre la Ciudad/El Colegio Mexiquense/Gobierno de la Ciudad de México/Miguel Ángel Porrúa.

Santos, M. (1996). Metamorfosis del espacio habitado. Barcelona: Oikos-Tau.

Santos, M. (2000). La naturaleza del espacio. Técnica y tiempo, razón y emoción. Barcelona: Ariel Geografía.

Sánchez, G. S. (2008). Planeación moderna de ciudades. México, D. F.: Trillas.

Singer, P. (1989). Economía política de la urbanización. México, D. F.: Siglo XXI.

Tomas, F. (1996). Del proyecto urbano al proyecto de ciudad. En Anuario de estudios urbanos, no. 3. México, D. F.: Universidad Autónoma Metropolitana-A.

Toussaint, M. (comp.). (2004). Belice: Textos de su historia, 1670-1981. Distrito Federal: Instituto de Investigaciones "Dr. José María Luis Mora”.

Recepción: 9 de febrero de 2012

Evaluación. 16 de marzo de 2012

Aprobación: 4 de julio de 2012 